\title{
Cooperation or Competition: An Evolutionary Game Study between Commercial Banks and Big Data-Based E-Commerce Financial Institutions in China
}

\author{
Yi Zhao, ${ }^{1}$ Dong Li, ${ }^{1}$ and Liqiang Pan $^{2}$ \\ ${ }^{1}$ School of Management, Harbin Institute of Technology, Harbin 150001, China \\ ${ }^{2}$ School of Computer Science and Technology, Harbin Institute of Technology, Harbin 150001, China \\ Correspondence should be addressed to Yi Zhao; 12b910045@hit.edu.cn
}

Received 24 October 2014; Revised 13 January 2015; Accepted 30 January 2015

Academic Editor: Chuanxi Qian

Copyright (C) 2015 Yi Zhao et al. This is an open access article distributed under the Creative Commons Attribution License, which permits unrestricted use, distribution, and reproduction in any medium, provided the original work is properly cited.

\begin{abstract}
On the premise of participants' bounded rationality and information asymmetry, this paper focuses on the cooperation or competition relationship between Chinese e-commerce financial institutions and commercial banks from the perspective of dynamic game. Theoretical mathematical model is built to analyze an evolutionary stable strategy under different conditions. We adopt real-life data set collected in Alibaba's network credit loan business case and Jingdong's supply chain financing business case to verify the evolution process of cooperation and competition relationship. The results show that (cooperation, cooperation) is bound to be the evolutionary stable strategy (ESS) and cooperation tends to be increasingly in-depth and expansive for commercial banks as well as e-commerce financial institutions in China. The complementarity of participants' core competitiveness is explored as the root of cooperation. Finally, strategic suggestions are put forward on cooperation between e-commerce financial institutions and commercial banks.
\end{abstract}

\section{Introduction and Literature Review}

The internet-based financing mode has been developing rapidly in China. It has been viewed as the third financing mode, which is different from indirect financing of commercial banks and direct financing of capital markets [1]. It includes six kinds of modes: the third-party payment, P2P, big data-based financing, crowd funding, internet-based traditional financial institutions, and internet-financial portal website [2]. The big data-based financing mode is the most well known, which has the most significant involvement and impact on the society and economy $[3,4]$. The big databased financing mode has been defined as a collective mode of financing service, including analyzing a large number of unstructured data by cloud computing and big data analysis technology. We combine it with traditional financial services to develop economics and financial work creatively [2]. Nowadays, the most representative model of the big databased financing mode in China includes e-commerce platform, big-data, and financial service. The relationship among them is that the e-commerce platform is the carrier of the big data. The big data is the core and foundation of the big databased financing mode and all financial services are dependent on the big data from e-commerce platform. The prior study is insufficient. We use Alibaba and Jingdong finance corporation as case study, representatives of e-commerce financial institutions in China. They are gathering the historical ecommerce trade information and other data of the customer and further applying other advanced technologies such as cloud computing to provide credit rating, small-sum loan, and guaranteeing service for e-commerce customers who demand loaning or other fund-raising services under the conditions of the controllable risk.

The $\mathrm{B} 2 \mathrm{~B}$ e-commerce transactions in China reached 8.2 trillion RMB in 2013, increased by $31.2 \%$ compared with the same period of last year [5]. China E-Commerce Research Center (CERC) assumes that the domestic medium-small and microsized enterprises (MSMEs) who use third-party ecommerce platforms (including the same company registered on different platforms and without duplicate registrations 
TABLE 1: Comparative advantages between e-commerce financial institutions and commercial banks.

\begin{tabular}{|c|c|c|c|c|c|c|c|c|c|}
\hline & Trade cost & Information & $\begin{array}{c}\text { Customer } \\
\text { experience }\end{array}$ & $\begin{array}{c}\text { Service } \\
\text { scope }\end{array}$ & $\begin{array}{c}\text { Regulatory } \\
\text { arbitrage }\end{array}$ & Capital & $\begin{array}{c}\text { Professional } \\
\text { ability }\end{array}$ & Security & $\begin{array}{c}\text { Credit } \\
\text { conditions } \\
\end{array}$ \\
\hline $\begin{array}{l}\text { E-commerce } \\
\text { financial } \\
\text { institutions }\end{array}$ & * & * & * & & * & & & & \\
\hline $\begin{array}{l}\text { Commercial } \\
\text { banks }\end{array}$ & & & & ※ & & $*$ & * & * & * \\
\hline
\end{tabular}

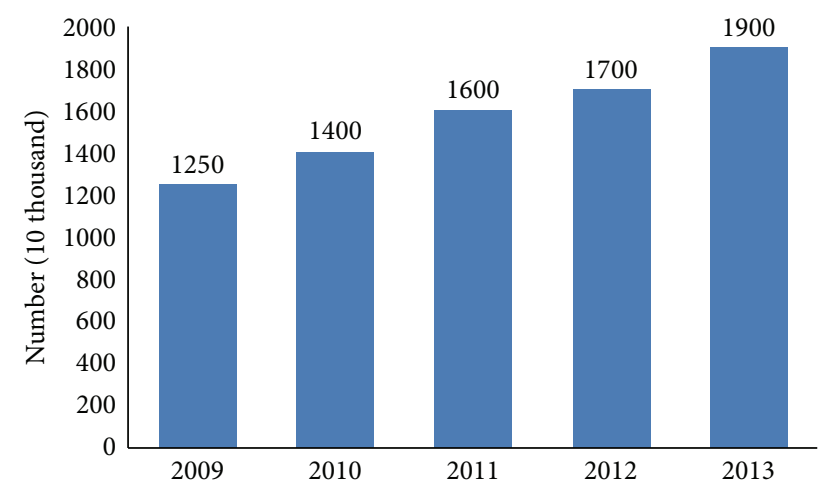

FIGURE 1: The growth trend of MSMEs with e-commerce platform (2009-2013). Data source: China E-Commerce Research Center (CERC).

on the same platform) would exceed 20 million, which offers a good opportunity for the rapid development of big data-based Chinese e-commerce financial institutions. The detailed data has been obtained from CERC, while the growth trend of MSMEs applying the e-commerce platform is shown in Figure 1.

With the professional business model and value creation style, Chinese e-commerce financial institutions on the basis of big data have direct effect on the traditional business of commercial banks. Chinese e-commerce financial institutions and commercial banks have advantages, respectively, particularly in trade cost, information, customer experience, service scope, regulatory arbitrage, capital, financial professional ability, security, and credit conditions (for a review, see Xie and Zou, 2012 [1]; Yan and Sun, 2014 [6]; CheDeyun, 2014 [7]; Sun and Bao, 2010 [8]; Hinson et al., 2008 [9]), as detailed in Table 1.

The comparative advantage between e-commerce financial institutions and commercial banks in China is quite obvious from Table 1 . Neither of them can be replaced by the other. In other words, the comparative advantage is the basic premise of both corporations' competition or cooperation [10]. It is possible that there would be intense competition between both corporations in some financial services markets, although they might carry out cooperation based on their own comparative advantage in some fields. When cooperation and competition exist simultaneously between the two corporations, there would seem to be some contradictory relationship between the binary opposition. The relationship is defined as coopetition [11].
Coopetition was firstly put forward by Nalebuf and Brand Enburger in the School of Management of Yale in 1990s. It was defined as the fact that corporations cooperate with each other and they struggle to achieve their competitive advantage, respectively.

Coopetition's duality is a strategic conception of competition in the cooperation and the process which integrates competition and cooperation [12]. It is not only a combination of cooperation and competition, but also a sort of artistic state in strategy and a dynamic evolutionary process of cooperation and competition relationship between corporations which may perform mutual transformation and dependence [13].

The process of coopetition is a dynamic process, performing continuous choice making. Coopetition games include five factors, which are known as "PARTS." " $P$ " represents "player" referring to the entire staff of enterprises; " $A$ " represents "added values" which refers to each member's contribution on their own resource and capability; " $R$ " stands for "rules" which focuses on the expected profits and operational risks distributed by the protocol according to different members' resources and capabilities; " $T$ " is proxy for "tactics" suggesting that the members trust each other and establish one common target; "S" represents "scope" which points to the cooperative range and time on the basis of its own resource and capability and so forth [14].

It seems that any change may lead to a variation of relationship in the ways of coopetition [15]. As a result, to a certain extent, the coopetition relationship between e-commerce financial institutions and commercial banks in China is more complex and flexible. The Evolutionary Game Theory provides a new method of dynamic "coopetition" relationship in the social and economic domain [16]. Considering the bounded rationality of every player in this theory, the game equilibrium solution cannot be achieved once. Conversely, with the repetitive games, each player can find the optimal behavior strategy for himself through gradual development and improvement and finally form the evolutionary stable strategy (ESS) [17].

The Evolutionary Game Theory has been applied in various fields by foreign researchers. For instance, Friesz et al. (2005) set up the model of network yield management in the service providers in oligarch competition pricing strategy [18]. Perez-Guirao et al. (2008) applied this theory in the sensor node power of wireless sensor networks in resource management [19]. Yang et al. (2011) established sufficient conditions for the existence of an admissible controller to ensure the asymptotical stability of the resulting closed-loop system and gave a numerical example to illustrate the proposed 
design method [20]. Yang et al. (2014) built up a new dynamic Cournot duopoly game model with team players in exploitation of a renewable resource [21].

However, the existing literature has little research on the relationship between Chinese big data-based e-commerce financial institutions and commercial banks, less application of mathematical logic methodologies [22, 23]. The coopetition relationship between Chinese e-commerce financial institutions and commercial banks would be analyzed in detail from the prospective of evolutionary game in the paper.

\section{The Fundamental Hypothesis}

(H1) Let $I=\{1,2\}$ represent the two bounded rational players in the game, respectively, that is, a commercial bank and big data-based e-commerce financial institutions. Moreover, let $S 1=S 2=$ \{competition, cooperation $\}$ be the strategic set of each participant. That is to say, there are two strategies for each player to choose. Cost needs to be paid when the two players cooperate, while the cost is 0 on the contrary.

(H2) When the two players choose cooperation, both of them provide a part of resource of their own and share the benefits from transaction to each other. When both of them choose competition, neither would like to cooperate with each other, indicating that each one provides client-oriented financial services, pays transaction costs, and earns net income alone.

If one player chooses cooperation and gives his own resource to the other, the other one chooses competition and then could complete the transaction alone without paying any cost. The net income is uncertain for each player who provides resource. Therefore, the cost of cooperation is definitely not less than they should spend in cooperation of two sides. Meanwhile, player who gets the resource will attain all the income of the transaction and the transaction costs should be considered as 0 .

(H3) When both the commercial bank and the ecommerce financial institution choose cooperation together, $\alpha A(\alpha \geq 1, A \geq 0)$ and $C_{1}$ are the income and cost of the commercial bank, respectively, and then the net income of the commercial bank should be $\alpha A-C_{1}$. Similarly, $\beta B(\beta \geq 1$, $B \geq 0)$ and $C_{2}$ are the income and cost of the e-commerce financial institution, respectively, and then the net income of the e-commerce financial institution should be $\beta B-C_{2}$. $\alpha$ $(\alpha \geq 1)$ and $\beta(\beta \geq 1)$ which means the degree of the cooperation are, respectively, known as the cooperation coefficients for two sides.

(H4) When the commercial bank and the e-commerce financial institution both choose competition, $A_{1}$ and $B_{1}$ $\left(A_{1}, B_{1} \geq 0\right)$ are the income of the commercial bank and the e-commerce financial institution, respectively.

(H5) When the commercial bank prefers cooperation while the e-commerce financial institution prefers competition, $A-C_{1}^{\prime}\left(C_{1}^{\prime} \geq C_{1} \geq 0\right)$ and $B$ are the net income of the commercial bank and the e-commerce financial institution, respectively. On the contrary, when the commercial bank prefers competition while the e-commerce financial institution prefers cooperation, $A$ and $B-C_{2}^{\prime}\left(C_{2}^{\prime} \geq C_{2} \geq 0\right)$ are
TABLE 2: Coopetition game payoffs matrix.

\begin{tabular}{lcc}
\hline $\begin{array}{l}\text { Commercial } \\
\text { bank }\end{array}$ & $\begin{array}{c}\text { E-commerce financial institution } \\
\text { Cooperation }\end{array}$ & Competition \\
\hline Cooperation & $\alpha A-C_{1}, \beta B-C_{2}$ & $A-C_{1}^{\prime}, B$ \\
Competition & $A, B-C_{2}^{\prime}$ & $A_{1}, B_{1}$ \\
\hline
\end{tabular}

the net income of the commercial bank and the e-commerce financial institution, respectively.

(H6) $p(0 \leq p \leq 1)$ is the probability for the commercial bank which chooses cooperation, and then $1-p$ is the probability for competition. $q(0 \leq q \leq 1)$ is the probability for the e-commerce financial institution which chooses cooperation, and then $1-q$ is the probability for competition.

On the basis of mentioned hypothesis above, the payoffs matrix is in Table 2 .

\section{Model and Analysis}

Based on payoffs matrix above, the commercial bank may choose cooperative or competitive strategy, as shown below:

$$
\begin{gathered}
E\left(U_{1}\right)_{p}=q\left(\alpha A-C_{1}\right)+(1-q)\left(A-C_{1}^{\prime}\right), \\
E\left(U_{1}\right)_{1-p}=q A+(1-q) A_{1} .
\end{gathered}
$$

Average payoffs of the mixed strategy chosen by the bank are shown blow:

$$
E\left(\bar{U}_{1}\right)=p E\left(U_{1}\right)_{p}+(1-p) E\left(U_{1}\right)_{1-p} .
$$

If the expected payoffs of a particular strategy are more than the average payoffs of the mixed strategy, this strategy will tend to be replicated. According to the replicator dynamics of evolution games, assume that the relative adjustment speed of its dynamics change which can be represented by differential equation is proportional to the range of payoffs that is more than the average payoffs. The replicator dynamics equation including independent variables is shown below:

$$
\frac{d p}{d t}=p\left[E\left(U_{1}\right)_{p}-E\left(\bar{U}_{1}\right)\right] .
$$

Similarly, the big data-based e-commerce financial institution chooses cooperative and competitive strategy, respectively, as shown below:

$$
\begin{gathered}
E\left(U_{2}\right)_{q}=p\left(\beta B-C_{2}\right)+(1-p)\left(B-C_{2}^{\prime}\right), \\
E\left(U_{2}\right)_{1-q}=p B+(1-p) B_{1} .
\end{gathered}
$$

Average payoffs of the mixed strategy chosen by the big databased e-commerce financial institution are shown below:

$$
E\left(\bar{U}_{2}\right)=q E\left(U_{2}\right)_{q}+(1-q) E\left(U_{2}\right)_{1-q} .
$$

Similarly, it can be concluded that replicator dynamics equation including independent variables is shown below:

$$
\frac{d q}{d t}=q\left[E\left(U_{2}\right)_{q}-E\left(\bar{U}_{2}\right)\right]
$$


TABLE 3: Stability test calculations of local equilibrium solutions.

\begin{tabular}{lcc}
\hline Local equilibrium solutions & Det $J$ & $\operatorname{Tr} J$ \\
\hline$O(0,0)$ & $\left(A-A_{1}-C_{1}^{\prime}\right)\left(B-B_{1}-C_{2}^{\prime}\right)$ & $A-A_{1}-C_{1}^{\prime}+B-B_{1}-C_{2}^{\prime}$ \\
$A(0,1)$ & $\left(-A+\alpha A-C_{1}\right)\left(-B+B_{1}+C_{2}^{\prime}\right)$ & $-A+C_{1}-B+B_{1}+C_{2}^{\prime}$ \\
$B(1,0)$ & $\left(-A+A_{1}+C_{1}^{\prime}\right)\left(-B+\beta B-C_{2}\right)$ & $A+A_{1}+C_{1}^{\prime}-B+\beta B-C_{2}$ \\
$C(1,1)$ & $\left(A-\alpha A+C_{1}\right)\left(B-\beta B+C_{2}\right)$ & $A+C_{1}+B-\beta B+C_{2}$ \\
$D$ point & $X$ & $\mathbf{0}$ \\
\hline
\end{tabular}

Let

$$
\begin{aligned}
& \frac{d p}{d t}=p\left[E\left(U_{1}\right)_{p}-E\left(\bar{U}_{1}\right)\right]=0, \\
& \frac{d q}{d t}=q\left[E\left(U_{2}\right)_{q}-E\left(\bar{U}_{2}\right)\right]=0 .
\end{aligned}
$$

Consequently, five local equilibrium solutions $(p, q)$ can be calculated by Mathematica 9.0, as shown in Table 3: $O:(0,0)$, $A:(0,1), B:(1,0), C:(1,1), D:\left(\left(-B+B_{1}+C_{2}^{\prime}\right) /(-2 B+\beta B+\right.$ $\left.\left.B_{1}-C_{2}+C_{2}^{\prime}\right),\left(-A+A_{1}+C_{1}^{\prime}\right) /\left(-2 A+\alpha A+A_{1}-C_{1}+C_{1}^{\prime}\right)\right)$.

Based on method offered by Friedman [24], the evolutionary stability of the whole game can be concluded by calculating Jacobi determinant of replicator dynamics equation (8). Let $J$ represent Jacobi matrix of (8); then its determinant and trace are Det $J$ and $\operatorname{Tr} J$. Det $J>0$ and $\operatorname{Tr} J<0 \Leftrightarrow$ the local equilibrium solutions $(p, q)$ is ESS; if $\exists(p, q)$, Det $J<0 \Leftrightarrow(p, q)$ is saddle point:

$$
\begin{aligned}
X= & -\left(A(\alpha-1)+A_{1}-C_{1}+C_{1}^{\prime}\right)\left(A(\alpha-1)-C_{1}\right) \\
& \cdot\left(-A+A_{1}+C_{1}^{\prime}\right)\left(B(\beta-1)-C_{2}\right)\left(-B+B_{1}+C_{2}^{\prime}\right) \\
& \cdot\left(\left((\alpha-2) A+A_{1}-C_{1}+C_{1}^{\prime}\right)^{2}\right. \\
& \left.\cdot\left(B(\beta-2)+B_{1}+C_{2}^{\prime}-C_{2}\right)\right)^{-1} \cdot
\end{aligned}
$$

On the basis of Friedman method [24], as the local equilibrium solutions stability test result shows, the evolutionary stability can be analyzed to conclude an ESS justification under different circumstances, as detailed below.

(1) Consider $A-A_{1}-C_{1}^{\prime}<0$ and $B-B_{1}-C_{2}^{\prime}<0 \Leftrightarrow$ Det $J>0$ and $\operatorname{Tr} J<0 \Leftrightarrow(0,0)$ is the ESS.

Namely, $A-C_{1}^{\prime}<A_{1}$ and $B-C_{2}^{\prime}<B_{1} \Leftrightarrow(0,0)$ is the ESS. Obviously, based on Table 2, the evolutionary stable strategy is that both of them choose competition together. This situation usually occurs before establishment of the ecommerce financial institution which needs to improve in such aspects as capital strength, professional financial ability, securities, and credit conditions. It is premature to cooperate with commercial banks for one e-commerce corporation, due to its lack of advanced financial professionals and not having formed a brand effect. According to credit investigation system of People's Bank for loan business, commercial banks would ignore the e-commerce financial institution's big databased customer credit evaluation system and would not have the sense of cooperation. According to hypothesis (H2), the net income of cooperation chosen by the e-commerce financial institution is less than that of noncooperation. Therefore, (competition, competition) serves as the evolutionary stable strategy (ESS) in this period.

(2) Consider $-A+\alpha A-C_{1}<0$ and $-B+B_{1}+C_{2}^{\prime}<0 \Leftrightarrow$ Det $J>0$ and $\operatorname{Tr} J<0 \Leftrightarrow(0,1)$ is the ESS.

Namely, $\alpha A-C_{1}<A$ and $B_{1}<B-C_{2}^{\prime} \Leftrightarrow(0,1)$ is the ESS. Obviously, based on Table 2, the evolutionary stable strategy is that the commercial bank chooses competition and the e-commerce financial institution chooses cooperation. This situation usually occurs when the e-commerce financial institution is equipped with conditions for cooperation in the fastgrowing period. By acquisition and training of talents and arising attention and propaganda of the mainstream media, the e-commerce financial institution can attain the cognition of customers, who reap better experience than commercial banks, leading to a good reputation in the financial industry. Thus, the brand image and its propagation form a virtuous circle to strengthen the competitive power of e-commerce financial institution. However, due to being unsatisfied with distribution of cooperation interests, commercial banks are unwilling to choose cooperation and (competition, cooperation) can be taken as an evolutionary stable strategy in this period.

(3) Consider $-A+A_{1}+C_{1}^{\prime}<0$ and $-B+\beta B-C_{2}<0 \Leftrightarrow$ Det $J>0$ and $\operatorname{Tr} J<0 \Leftrightarrow(1,0)$ is the ESS.

Namely, $A_{1}<\left(A-C_{1}\right)$ and $\beta B-C_{2}<B \Leftrightarrow(1,0)$ is the ESS. Obviously, based on Table 2, the evolutionary stable strategy is that the commercial bank chooses cooperation and the e-commerce financial institution chooses competition. When the e-commerce financial institutions are unsatisfied with distribution of cooperation interests and have basic conditions of self-operation, they are not willing to choose cooperation with commercial banks but choose self-operation instead. It is definitely possible that commercial banks lose their talents, customers, capital, profits, and even markets, if commercial banks operate and manage only in accordance with traditional thoughts of financial intermediaries, but not absorbing internet essence which is open, collaboration and sharing, and not paying enough attention to the customer experience and online service, especially to the analysis and use of customer information they owned. Because of all above, commercial banks choose cooperation to consolidate their main position in financial market, in order to maintain their sustainable development. Thus, (cooperation, competition) can be taken as an evolutionary stable strategy in this period.

(4) Consider $A-\alpha A+C_{1}<0$ and $B-\beta B+C_{2}<0 \Leftrightarrow$ Det $J>0$ and $\operatorname{Tr} J<0 \Leftrightarrow(1,1)$ is the ESS. 
Namely, $A<\alpha A-C_{1}$ and $B<\beta B-C_{2} \Leftrightarrow(1,1)$ is the ESS. Obviously, based on Table 2 , the evolutionary stable strategy is that both of them choose cooperation together. This situation usually occurs when the e-commerce financial institutions have established their reputation in Chinese financial industry and are recognized by commercial banks. Hence, the commercial banks would begin to reexamine their own advantages and disadvantages and cooperate with ecommerce financial institutions, aiming at seeking a new reform based on this opportunity. E-commerce financial institutions realize their capital and other disadvantages in further financial services. They are willing to choose further cooperation with commercial banks. Consequently (cooperation, cooperation) can be seen as the evolutionary stable strategy in this period.

(5) For $D$ point, if $\beta>2$, then denominator of $X$ is positive; in the condition, obviously only if expression $(A(\alpha-$ 1) $\left.-C_{1}\right)\left(-A+A_{1}+C_{1}^{\prime}\right)\left(B(\beta-1)-C_{2}\right)\left(-B+B_{1}+C_{2}^{\prime}\right)>0$, $\left(\left(A(\alpha-1)+A_{1}-C_{1}+C_{1}^{\prime}\right)>0\right.$ obviously), then $X<0$. Namely, $D$ point is saddle point. Based on Table 2, it can be concluded that if both of them choose competition and cooperation together, $X$ is negative and $D$ point is saddle point. Therefore, the equilibrium solution of evolutionary game between the ecommerce financial institution and the commercial bank will be determined by probability $p$ and $q$ of their initial strategy chosen, respectively.

\section{Case Study}

The financial service offered by big data-based e-commerce financial institutions consists of two modes which are finance platform represented by Alibaba and supply chain finance represented by Jingdong at present [2]. To examine the effectiveness of the theoretical research mentioned above, this paper applies empirical analysis to Alibaba's network credit loan business and Jingdong's supply chain financing business.

4.1. Case 1: Alibaba's Network Credit Loan Business. As the first e-commerce financial business based on big data in China, Alibaba's network credit loan has operated for 12 years since 2002, which is the collateral-free and guarantee-free credit loan offered to customers with financing demand on the basis of big data and credit evaluation technology such as cloud computing supported by Alibaba's platform. The case should be analyzed in four phases to explore the evolutionary path of competition and cooperation relationship between ecommerce financial institutions and commercial banks.

(1) Preparation Stage: March 2002-April 2007. Alibaba's network credit loan business was grounded in the e-commerce customer credit evaluation system with data as its core. The system was originated from the TrustPass member service launched in March 2002 which required Alibaba's members to establish and demonstrate their credit files on the website. Having accumulated data for two years through the system, Alibaba released TrustPass Index in March 2004, which measured enterprises' credit status via scientific credit evaluation system. The credit evaluation system needed constant improvement as the e-commerce customer credit database involving a growing number of enterprises. However, the personal credit information database of the People's Bank was officially operated in January 2006. Additionally, the national network for enterprise credit information database of the People's Bank was applied in July 2006. As major users of the credit system of People's Bank, commercial banks lacked confidence on Alibaba's imperfect credit evaluation system and were inclined to be uncooperative with Alibaba. According to hypothesis $(\mathrm{H} 2)$, the net income of cooperation chosen by e-commerce financial institutions was less than that of noncooperation. Therefore, (noncooperation, noncooperation) served as the evolutionary stable strategy (ESS) in this period.

(2) Trial Stage: May 2007-May 2010. On May 16, 2007, Alibaba formally signed with China Construction Bank (CCB) to colaunch network credit loan for e-commerce customers, indicating that Alibaba started to seek collaboration with banks consciously and released collateral-free credit loans on the basis of e-commerce customer data. During the collaboration, Alibaba took charge of providing e-commerce customer credit database while CCB was mainly responsible for offering loans to the customers, with the annual interest rate of $8 \%-12 \%$ and the amount from 200,000 yuan to $2,000,000$ yuan. The cost of each single network credit loan was far less than that of traditional loan. And the loan had a term of one year or less. In the later phase of cooperation, Alibaba asked for $2 \%$ of the loan amount as its service charge. By the end of 2009, the loan service had attracted 1,470 customers, the balance reached 2,899,090,000 yuan, and the nonperforming ratio was assessed at $1 \%$, lower than that for traditional medium and small-sized enterprises (MSEs) which reached $1.73 \%$ [25].

As analyzed above, the game strategies of Alibaba and CCB were analyzed as follows: a network credit loan was set as $N(N \in[200000,2000000])$, the term as one year, the interest rate as $10 \%$, and the cost as $C$. When Alibaba chose cooperation while CCB preferred noncooperation, according to (H2), CCB would complete the loan and obtain total earnings without any payment to Alibaba. Therefore the net income of CCB would be $A=10 \% N-C$. When both CCB and Alibaba preferred cooperation, the net income of CCB would be $\alpha A-C_{1}=(10 \%-2 \%) N-C=8 \%-C$. Obviously, $\alpha A-$ $C_{1}<A$. If Alibaba preferred cooperation, CCB would earn more net income by choosing cooperation than that of noncooperation.

Given that CCB tended not to cooperate, when Alibaba chose noncooperation, the network credit loan would fail to exist. Therefore, the net income of Alibaba was $B_{1}=0$. However, when Alibaba was willing to cooperate, then $B-C_{2}^{\prime}=$ $2 \% N-C_{2}^{\prime}$. According to Sun Quan, the CEO of Alibaba Microcredit Co., Ltd, each traditional loan offered by commercial banks held a cost of 2,000 yuan. Thus, the cost of network credit loan stayed far less than that of traditional loan. Let $0<C<C_{2}^{\prime}<2000$; then it was clear that $2 \% N-C_{2}^{\prime}>$ 0 if $N$ outnumbered 100,000 yuan. But the amount of any network credit loan $N \in[200000,2000000]$; it was obvious that $2 \% N-C_{2}^{\prime}>0$. Namely, $B_{1}<B-C_{2}^{\prime}$. It indicated that 
if CCB fails to cooperate, Alibaba achieved less net income when it chose noncooperation compared to cooperation.

In conclusion, the game features in this period were in accordance with theoretical conclusion (2) and met the conditions of $\alpha A-C_{1}<A$ and $B_{1}<B-C_{2}^{\prime}$. Thus, (noncooperation, cooperation) behaved as the ESS in this period. In fact, shortly after Alibaba required $2 \%$ of loan amount as its service fee, $\mathrm{CCB}$ refused the request for it would increase the burden of customers and add risks to the bank. Since then, collaborations between the bank and Alibaba gradually collapsed and finally ended.

(3) Self-Operation Stage: June 2010-June 2014. On June 8, 2010, Zhejiang Alibaba Microcredit Co., Ltd. was founded, marking the birth of the first big data-based e-commerce financial institution in China. On June 21, 2011, Chongqing Alibaba Microcredit Co., Ltd. was established. And on August 5, 2013, Chongqing Alibaba Small and Micro-Sized Small-Sum Loan Co., Ltd. went into run. The three microcredit corporations, whose registered capital totaled 1.8 billion yuan, were operated by Alibaba to conduct network credit loan business. As the first e-commerce customer-oriented microcredit corporation, Alibaba Microcredit Co., Ltd. (AMCL) provided a new approach for small and microsized enterprises (SMEs) which were hard to obtain loans from commercial banks [26].

According to statistics of AMCL, the annual interest rate of loans was $18 \%-21 \%$. The loan amount was not more than one million yuan and the term was not longer than one year. AMCL's CEO Sun Quan stated that the cost for each loan was 2.3 yuan while that of commercial banks reached 2,000 yuan approximately. By the first half of 2014, loans from AMCL had outnumbered 210 billion yuan in total to fund over 800,000 SMEs, the loan balance leveled 15 billion yuan, and the average balance for each SME was less than 40,000 yuan. The nonperforming ratio was assessed at $1 \%$, lower than that for Chinese SMEs which was $2 \%$.

The funds of AMCL contained its own capital and those from nonbank financial institutions. The reason that why AMCL did not choose banks lied in two aspects. On one hand, the interest rate would move up $20 \%-30 \%$ on the basis of benchmark interest rate, pushing up financing cost. On the other hand, the amount from banks could not meet the needs of AMCL. According to the Guiding Opinions of China Banking Regulatory Commission and the People's Bank of China on the Pilot Operation of Small-Sum Loan Companies released by China Banking Regulatory Commission, the balance of loans borrowed from banks by small-sum loan companies should not surpass $50 \%$ of its registered capital, asking that AMCL could borrow at most 900 million yuan from banks. In other words, AMCL loaned 2.7 billion yuan from banks at most, causing it to fail to satisfy its network credit loan business obviously. Therefore, AMCL chose nonbank financial institutions including securities, funds, trusts, and insurances as external sources in the period of self-operation.

On the basis of real-life data, the game strategies of AMCL and commercial banks were analyzed as follows: a network credit loan was set as $N(N \in[1000,1000000])$ with the term of one year, the annual interest rate of $20 \%$, and the cost for AMCL dealing with the loan of 2.3 yuan. The cost for commercial banks to deal with a single loan reached 2,000 yuan and the one-year loan benchmark interest rate of commercial banks was pegged at 6\% (July 6, 2012-November 21, 2014, the People's Bank of China). Suppose that AMCL tended not to cooperate; if commercial banks preferred noncooperation as well, the net income of the banks would be $A_{1}=$ $6 \% N-2000$. When the banks were willing to cooperate and offer funds to AMCL, their net income was $A-C_{1}^{\prime}=6 \%(1+$ $W \%) N-2000, W \in[20 \%, 30 \%]$. It was obvious that $A_{1}<A-$ $C_{1}^{\prime}$. Considering the noncooperation of AMCL, commercial banks would obtain more net income through choosing cooperation than that of noncooperation.

Suppose commercial banks would choose cooperation; when AMCL preferred cooperation as well, its net income stood at $\beta B-C_{2}=[20 \%-6 \%(1+W \%)] N-2.3, W \epsilon$ [20\%, 30\%]. When AMCL tended to noncooperation, its net income was $B=20 \% N-2.3$. Apparently $\beta B-C_{2}<B$; if commercial banks would like to cooperate, AMCL achieved more net income when it chose noncooperation compared to that of cooperation.

In conclusion, the features in this period were in line with theoretical conclusion (3) and met the conditions of $A_{1}<A-C_{1}^{\prime}$ and $\beta B-C_{2}<B$. Thus, (cooperation, noncooperation) became the ESS in this period. Actually, AMCL acquired capital mainly from asset securitization, through which the financing cost accounted for $6.5 \%-7 \%$ of the capital it achieved. The cost was lower compared with money borrowed from banks and the capital capacity borrowed from nonbank financial institutions reached several billion yuan. Therefore, AMCL did not establish cooperative relationship with commercial banks in this period.

(4) Cooperation Stage: July 2014 to Date. On July 22, 2014, AMCL and seven commercial banks including the Bank of China announced that they would conduct in-depth cooperation to provide big data-based advanced entrepreneur Loan for SMEs. It was the first collateral-free credit loan that commercial banks offered on the basis of credit evaluation system supported by Alibaba's big data platform. The annual interest rate of the loan was $8 \%-14 \%$ in which $1 \%-2.5 \%$ served as the income of AMCL. The loan amount ranged from one million yuan to ten million yuan with the term of not longer than one year. By August 22, 2014, 58 enterprises had passed audits and loans from banks totally 120 million yuan approximately.

With the adoption of real-life data, the game strategies of AMCL and commercial banks were analyzed as follows: set the amount of a network credit loan as $N(N \in$ $[1000000,10000000])$, the term of that as one year, the annual interest rate as $8 \%$ in which $1 \%$ served as AMCL's income, and the cost for dealing with the loan as $S$. Without commercial banks' collaboration, the one-year loan benchmark interest rate carried out 6\% (July 6, 2012-November 21, 2014, the People's Bank of China) for the loan. Therefore, suppose AMCL to be willing to cooperate; then net incomes of commercial banks by acting uncooperatively and cooperatively would be $A=6 \% N-S$ and $\alpha A-C_{1}=(8 \%-1 \%) N-S=7 \% N-S$, respectively. It was clear that $A<\alpha A-C_{1}$. That is, considering the cooperation of AMCL, commercial banks would obtain 
more net income when it chose cooperation compared to that of noncooperation.

Suppose that commercial banks would like to cooperate; when AMCL tended to cooperate as well, its net income was $\beta B-C_{2}=1 \% N$. Due to $N \in[1000000,10000000]$, it could be drawn that $\beta B-C_{2}$ would be not less than 10,000 . However, if AMCL preferred noncooperation, it had to self-run network credit loan business. The average balance for each SME was less than 40,000 yuan and the interest rate stood at $18 \%-21 \%$. Let the amount of some loan be 40,000 yuan at the interest rate of $21 \%$; the net income of AMCL stayed at $B=40000 \times$ $21 \%-2.3=8397.7$.

Obviously, $B<\beta B-C_{2}$. We implied that if commercial banks chose cooperation, AMCL would achieve more net income via cooperation than that of noncooperation.

In conclusion, the features in this period matched with theoretical conclusion (4) and met the conditions of $\alpha A-C_{1}$ and $B<\beta B-C_{2}$. Hence, (cooperation, cooperation) served as the ESS in this period. In fact, five commercial banks including ICBC and CMB addressed their willingness of collaborating with AMCL on July 28. Additionally, AMCL stated that there existed the likelihood of getting involved with more banks, even those abroad in the future. Thus, it can be implied that both AMCL and commercial banks would adopt cooperative strategy in future.

4.2. Case 2: Jingdong's Supply Chain Financing Business. Jingdong (JD), China's second largest e-commerce corporation smaller than Alibaba, set foot in financing business in 2012. Its supply chain financing business, as collaboration with commercial banks, has provided financing services for its partner suppliers. Considering that the collaboration has been deepened continuously in the past just two years, the author conducted in-depth analysis on the evolution of the cooperative relationship between JD and commercial banks on the basis of supply chain financing business.

On November 27, 2012, JD and the Bank of China signed a strategic cooperation agreement to colaunch supply chain financing business. JD provided the bank with information or guarantee for loan approval based on its 40,000 suppliers' transaction data and credit analysis. Meanwhile, the bank offered loans to suppliers in accordance with the information or guarantee from JD. According to the revelation of JD Finance Corporation, the annual interest rate of the loan rose by $10 \%-30 \%$ on the basis of benchmark interest rate and the term was up to one year. JD gained profits through charging for service fee whose rate averaged $0.03 \%$ of loan amount. By the end of November 2013, the accumulated loans had outnumbered 8 billion yuan, most of which held the term of not longer than one month. The amount of a single loan averaged 2 million to 3 million yuan, with the smallest and the largest at 0.2 million and 100 million, respectively. The income of supply chain financing business totaled 344 million yuan in 2013; with a cost of 8 million yuan, its gross profit rate reached $97.67 \%$.

Based on real-life data, the game strategies of JD and commercial banks were analyzed as follows: set some supply chain loan as $N(N \in[200000,100000000])$, the loan term as one month, the interest rate as $6 \%(1+20 \%) / 12$ (i.e., $0.6 \%$ ), and the cost for banks dealing with the loan as $D$. JD's income of service fee read $0.03 \% \mathrm{~N}$ and its average net income of each loan reached $97.67 \% \times 0.03 \% N$.

Suppose that commercial banks would prefer noncooperation; then the one-year loan benchmark interest rate carried out 6\% (July 6, 2012-November 21, 2014, the People's Bank of China) for the loan. When JD tended to cooperate but commercial banks did not mean to, the net income of commercial banks would be $A=6 \% / 12 N-D=0.5 \% N-D$. When commercial banks chose cooperation with JD, the net income of commercial banks would be assessed at $\alpha A-C_{1}=$ $(0.6 \%-0.03 \%) N-D=0.57 \% N-D$. It was apparent that $A<$ $\alpha A-C_{1}$. Considering JD's cooperation, commercial banks would obtain more net income when it chose cooperation compared to that of noncooperation.

Suppose that commercial banks would choose cooperation. When JD preferred cooperation as well, the net income of JD's dealing with the loan would be $\beta B-C_{2}=97.67 \% \times$ $0.03 \% N, N \in[200000,100000000]$. On the contrary, if JD chose noncooperation, the business would fail to conduct and JD's net income would be $B=0$ correspondingly. Obviously, $B<\beta B-C_{2}$. Given that commercial banks were cooperative, JD would acquire more net income when it chose cooperation compared to that of noncooperation.

Above all the features of this period were in accordance with theoretical conclusion (4) and matched the conditions of $A<\alpha A-C_{1}$ and $B<\beta B-C_{2}$. Therefore, (cooperation, cooperation) acted at the ESS of this period. Actually, JD has partnered with over 10 large-scale commercial banks in China such as ICBC. Additionally, JD also announced partnership with Grameen Bank on December 17, 2014, to explore the combination mode between services of its supply chain financing and offline microfinancing model. Hence, it could be concluded that both JD and commercial banks would be inclined to be cooperative in this period as well as in the future.

\section{Conclusion}

In this paper, an evolutionary mathematical model of coopetition relationship between big data-based e-commerce financial institutions and commercial banks is formulated to analyze evolutionary stable strategies under different conditions. We adopt real-life data collected in two cases to examine the evolution process of coopetition relationship. On the basis of above research, we can conclude (cooperation, cooperation) is bound to be the ESS and cooperation tends to be increasingly in-depth and expansive for commercial banks and e-commerce financial institutions in China. Furthermore, the complementarity of participants' core competitiveness is explored as the root of cooperation. The core competitiveness of e-commerce financial institutions is low-cost ecommerce customer credit evaluation capability on big data. The core competitiveness of commercial banks is their abundant capital strength. Finally, strategic suggestions are put forward on cooperation between e-commerce financial institutions and commercial banks as follows.

(1) First and foremost, the commercial banks should heighten their own capital adequacy ratio and asset 
quality. What is more, they should seek positively to cooperate with e-commerce financial institutions for win-win situation.

(2) E-commerce financial institutions should further improve their own big data-based e-commerce customer credit evaluation system. On this fundamental, they should seek expansively to cooperate with the commercial banks and other nonbank financial institutions.

\section{Conflict of Interests}

The authors declare that there is no conflict of interests regarding the publication of this paper.

\section{Acknowledgment}

This work was supported by the National Natural Science Foundation of China (NSFC) (Grant no. 61100030).

\section{References}

[1] P. Xie and C. Zou, "Research on internet based finance mode," Journal of Financial Research, no. 12, pp. 11-22, 2012.

[2] L. Mingxiong, T. Ying, and L. Yong, Internet Based Finance, China Financial \& Economic Publishing House, Beijing, China, 2013.

[3] H. Hailong, "Research of the internet finance with the core as ecommerce platform," Shanghai Finance, no. 8, pp. 18-23, 2013.

[4] F. Lin, M. J. Shaw, and M. Y. Chuang, "A unified framework for managing Web-based services," Information Systems and $e$ Business Management, vol. 3, no. 3, pp. 299-322, 2005.

[5] The 2013 Annual Chinese E-Commerce Market Data Monitoring Report, 2014, http://www.100ec.cn/zt/2010bgdz/.

[6] N. Yan and B. Sun, "Mode innovation and of network financing for SMEs," Science Technology Progress and Policy, no. 3, pp. 1-5, 2014.

[7] CheDeyun, "The change of commercial banks coopetition strategy in the Internet financial evolution," International Finance, no. 2, pp. 7-10, 2014.

[8] X. W. Sun and J. L. Bao, "Research on the innovation and development of the third-party B2B e-commerce model of China," in Proceedings of the 3rd International Conference on Advanced Computer Theory and Engineering (ICACTE '10), pp. V4-317-V4-319, Chengdu, China, August 2010.

[9] R. Hinson, R. Boateng, and O. Jull Sorensen, "E-business financing: preliminary insights from a developing economy context," Journal of Information, Communication and Ethics in Society, vol. 6, no. 3, pp. 196-215, 2008.

[10] H. Zhaoyang, "The research of collaborative competition," Journal of Central University of Finance \& Economics, no. 2, pp. 5557, 2004.

[11] M. Bengtsson and S. Kock, ““'Coopetition” in business networks: to cooperate and compete simultaneously," Industrial Marketing Management, vol. 29, no. 5, pp. 411-426, 2000.

[12] A. M. Brandenburger and B. J. Nalebuff, Coopetition, Bantam Doubleday, New York, NY, USA, 1998.

[13] T. Lanjing, "Reflections on the concerted strategy of cooperative enterprises," Theory Monthly, no. 11, pp. 159-160, 2003.
[14] A. M. Brandenburger and B. J. Nalebuff, "The right game: use game theory to shape strategy," Harvard Business Review, no. 7, pp. 57-71, 1995.

[15] S. Miyuan and P. Yi, "Stability analysis on strategy alliance," Journal of Industrial Engineering and Engineering Management, no. 3, pp. 76-78, 2000.

[16] O. Gomes, "Discrete dynamics in evolutionary games," Discrete Dynamics in Nature and Society, vol. 2012, Article ID 416789, 23 pages, 2012.

[17] J. W. Weibull, Evolutionary Game Theory, MIT Press, Cambridge, Mass, USA, 1995.

[18] T. L. Friesz, R. Mookherjee, and M. A. Rigdon, "An evolutionary game-theoretic model of network revenue management in oligopolistic competition," Journal of Revenue \& Pricing Management, vol. 4, no. 2, pp. 156-173, 2005.

[19] M. D. Perez-Guirao, R. Luebben, T. Kaiser, and K. Jobmann, "Evolutionary game theoretical approach for IR-UWB sensor networks," in Proceedings of the IEEE International Conference on Communications Workshops (ICC '08), pp. 107-111, IEEE, Beijing, China, May 2008.

[20] R. Yang, P. Shi, G.-P. Liu, and H. Gao, "Network-based feedback control for systems with mixed delays based on quantization and dropout compensation," Automatica, vol. 47, no. 12, pp. 2805-2809, 2011.

[21] Y. Yang, J. Ma, and H. Tu, "Chaotic characteristics and application of cooperative game and evolutionary game," Discrete Dynamics in Nature and Society, vol. 2014, Article ID 908093, 13 pages, 2014.

[22] OuBai, "Governance of innovation network in the case of Alibaba," in Proceedings of the IEEE International Symposium on Management of Technology (ISMOT '12), pp. 81-86, Zhejiang, China, November 2012.

[23] P. Tao, "Credit of small and micro businesses in the age of big data: concurrently the cooperation between bank and e-commerce companies," Times Finance, no. 5, pp. 232-233, 2013.

[24] D. Friedman, "Evolutionary games in economics," Econometrica, vol. 59, no. 3, pp. 637-666, 1991.

[25] J. Yang, Z. Xu, J. Zhao, and Z. Ye, "Comparison and enlightenment among three micro-credit models," Shanghai Finance, no. 9, pp. 81-89, 2010.

[26] F.-R. Lin, R.-W. Po, and C. V. C. Orellan, "Mining purchasing decision rules from service encounter data of retail chain stores," Information Systems and e-Business Management, vol. 9, no. 2, pp. 193-221, 2011. 


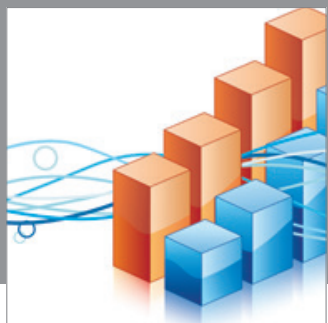

Advances in

Operations Research

mansans

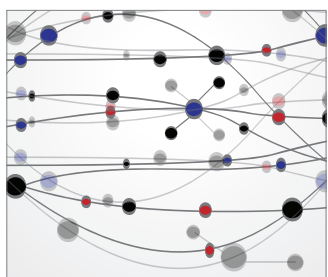

The Scientific World Journal
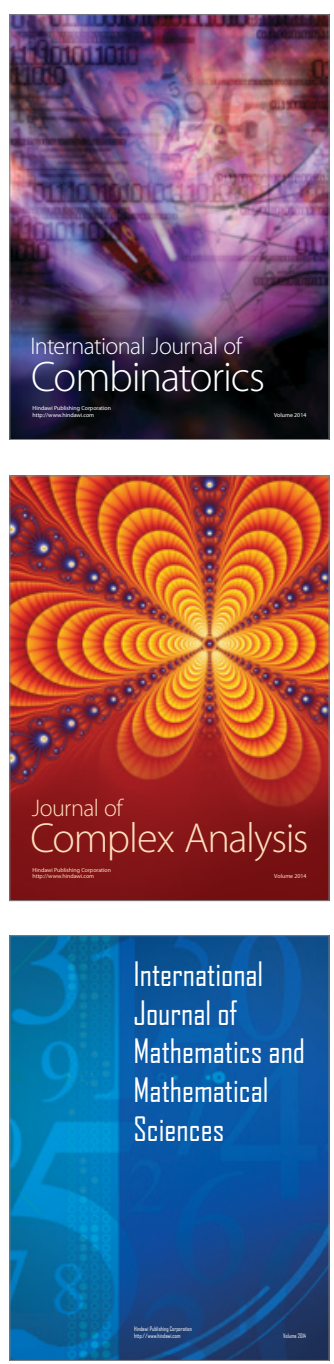
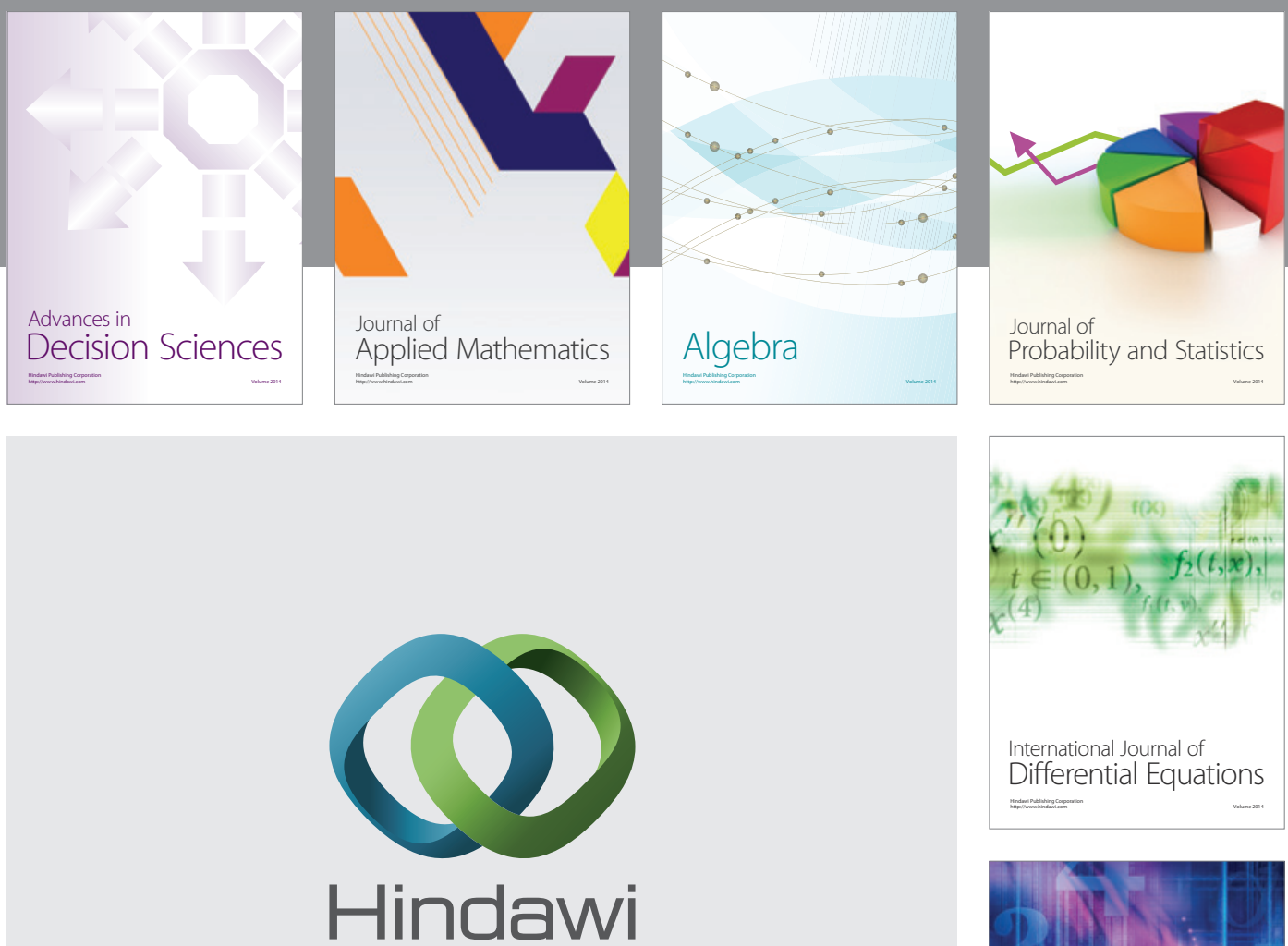

Submit your manuscripts at http://www.hindawi.com
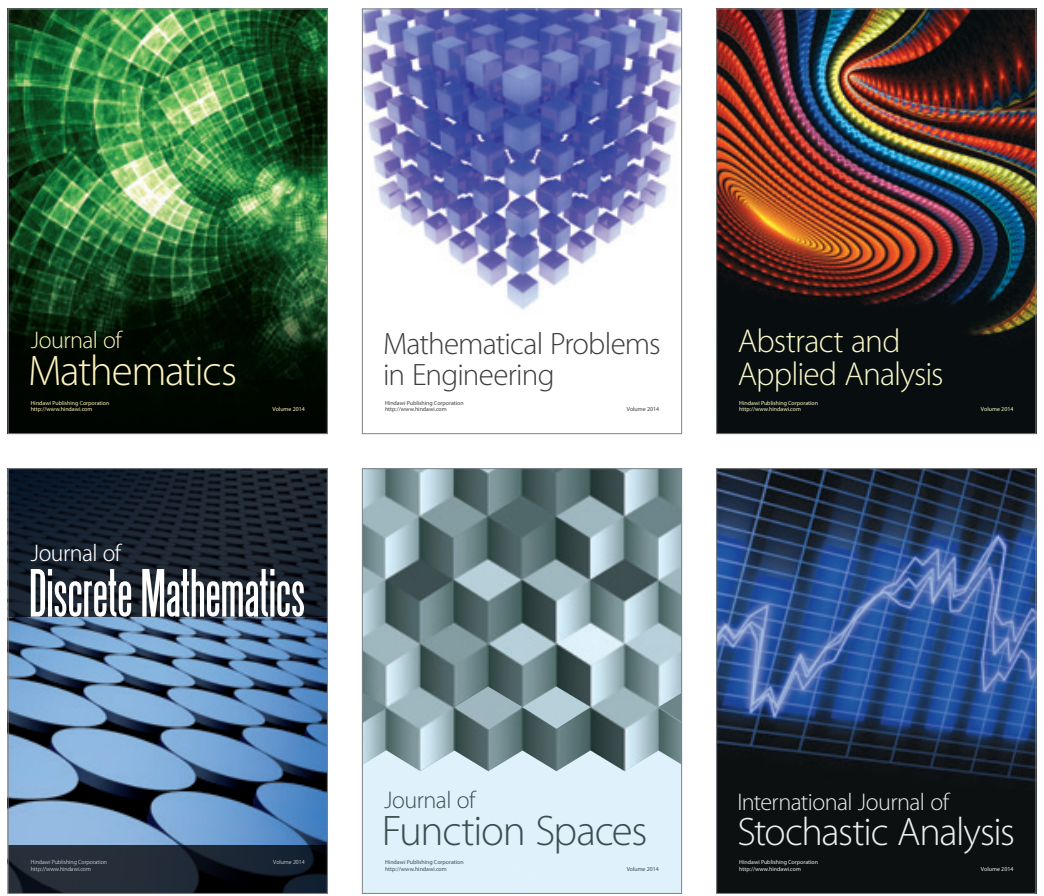

Journal of

Function Spaces

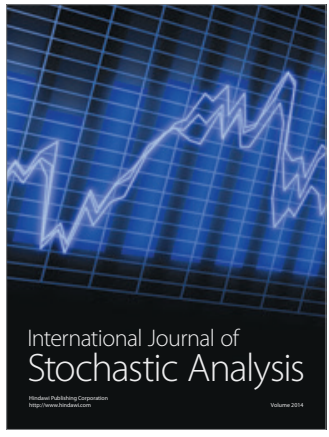

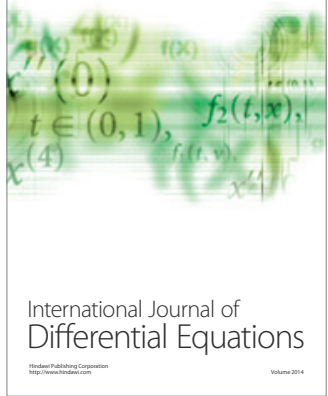
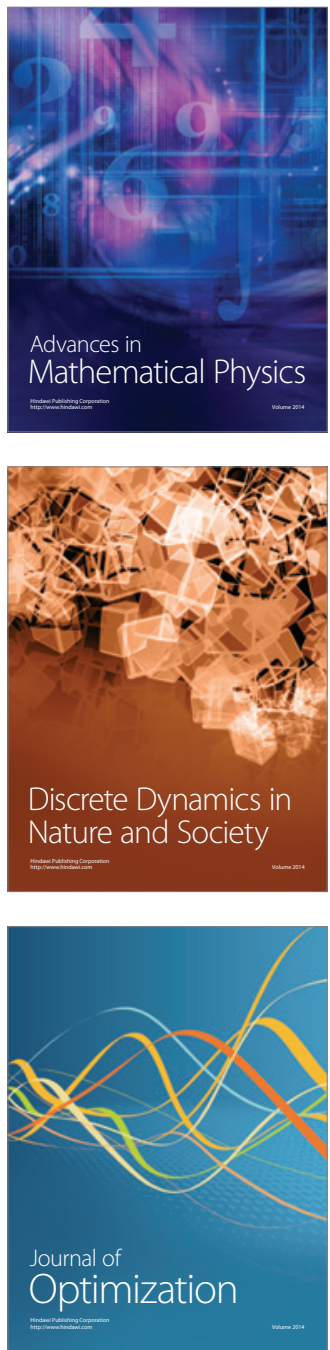